\title{
EL CONCEPTO DE HEGEMONÍA EN LAS RELACIONES INTERNACIONALES: UNA CRITTICA A ANDREAS ANTONIADES
}

\section{THE CONCEPT OF HEGEMONY IN INTERNATIONAL RELATIONS: A CRITICISM OF ANDREAS ANTONIADES}

\section{Eduardo Molina Campano \\ Laboratorio de Ideas y Prácticas Políticas (UPO), Sevilla, España Edula7@hotmail.com}

Recibido: noviembre de 2019

Aceptado: diciembre de 2019

\begin{abstract}
Palabras claves: hegemonía, relaciones internacionales, economía política internacional, coerción, consentimiento y movimiento de poder.
\end{abstract}

Keywords: hegemony, international relations, international political economy, coercion, consent and power movement.

Resumen: Esta investigación pretende analizar los diferentes enfoques teóricos existentes en la disciplina de las relaciones internacionales con relación al concepto de hegemonía. Para ello se indagará en el origen gramsciano del término y en su evolución posterior hasta llegar al debate que nos concierne. Dentro de esta discusión el autor se centrará en el estudio de la propuesta de Andreas Antoniades definida como "Movimiento de Poder" con el objeto de someterla a una crítica desde la perspectiva de la Economía Política Internacional Crítica. Esta perspectiva que el autor dejará semi planteado implícitamente tiene dos elementos fundamentales que la caracterizan, a saber: toma a la sub disciplina de la economía política internacional como enfoque para el análisis de las relaciones internacionales pero en segundo lugar lo hace desde una posición materialista crítica respecto a las escuelas vigentes en dicha subdisciplina.

Abstract: This research aims to analyze the different theoretical approaches existing in the discipline of international relations in relation to the concept of hegemony. For this, the Gramscian origin of the term and its subsequent evolution will be investigated until it reaches the debate that concerns us. Within this discussion the author will focus on the study of the proposal of Andreas Antoniades defined as "Power Movement" in order to subject it to criticism from the perspective of the Critical International Political Economy. This perspective that the author will leave semi implicitly raised has two fundamental elements that characterize it, namely: it takes the sub discipline of international political economy as an approach to the analysis of international relations but secondly it does so from a critical materialist position regarding the schools in force in said subdiscipline. 


\section{Introducción}

La noción de hegemonía se ha convertido en un concepto de uso frecuente en las Relaciones Internacionales. Empero su utilización suele ser imprecisa y volátil epistemológicamente hablando. Hegemonía es un término complejo de origen fundamentalmente gramsciano con dos piedras basales que se remontan a Tucídides (2015) y a Maquiavelo (2012) y con unos antecedentes cercanos que giran en torno a los escritos de los dirigentes de la socialdemocracia rusa. Posee potencialmente la doble característica de poder ser aplicado tanto a las relaciones sociales de poder internas en un Estado-nación como a las externas que gravitan en el sistema internacional. Mediante la articulación metodológica o estratégico-táctica de los instrumentos de la coerción y el consentimiento, la hegemonía suele ser la aspiración de cualquier sujeto en el plano nacional o internacional. Es un concepto que permite reflexionar sobre el poder, más allá de su apariencia, a través de las preguntas acerca de cuáles son las causas de dicho poder, cómo opera este para tratar de mantenerse en él y por qué declina o se pierde. Esta investigación estudiará los diferentes enfoques teóricos sobre la hegemonía en las RRII y se centrará en el análisis de la propuesta de Movimiento de Poder de Andreas Antoniades con el objeto de someterla a una crítica desde el enfoque de la Economía Política Internacional Crítica.

\section{El concepto de hegemonía}

\section{I El origen del concepto}

El término hegemonía, antes de que Gramsci (1981) lo adoptara, había sido utilizado por los dirigentes de la socialdemocracia rusa. Fue Axelrod ${ }^{1}$ quién la nombró por primera vez en 1901 en una carta a Stru$v^{2}$ para señalar una idea que ya había sido esbozada por Plejanov ${ }^{3}$ en relación con el papel que debía jugar el proletariado fabril en la lucha contra el absolutismo y en favor de la democracia (Anderson, 1981: 9). Debido a la debilidad de la burguesía rusa para asumir su tarea histórica contra el absolutismo, según preconizaba el paradigma marxista ortodoxo, el proletariado estaba obligado a irrumpir en la escena pública antes de tiempo y adoptar una tarea que no le correspondía por ser ajena a su naturaleza de clase. Este desajuste entre clase y tarea histórica es la base que explica el nacimiento de la idea de hegemonía ya que para llenar ese hiato se necesitaba intervenir subjetivamente articulando circunstancialmente a todas las clases oprimidas dispuestas a luchar contra el absolutismo bajo el liderazgo de la clase obrera (Laclau y Mouffe, 1987). En este sentido Lenin, en una carta a Plejanov, llegó a afirmar que la única forma posible de preparar una verdadera hegemonía de la clase obrera en Rusia radicaba en la creación de un periódico político que fungiera como organizador del movimiento de la clase (Anderson, 1981). La estrategia de la hegemonía del proletariado respecto de las otras clases oprimidas en el marco de la revolución burguesa en Rusia era una consigna común entre bolcheviques y mencheviques hasta que estos se separaron en el II Congreso del POSDR ${ }^{4}$ en 1903. A partir de ahí fueron los mencheviques los que dieron un paso atrás y retornaron a

1. Dirigente marxista y menchevique.

2. Piotr Struve, miembro redactor del Manifiesto del Partido Obrero Socialdemócrata Ruso. Luego se pasó al partido liberal kadete.

3. Fundador del marxismo ruso.

4. Partido Obrero Socialdemócrata Ruso. 
las tesis ortodoxas etapistas mientras que los bolcheviques buscaron darle forma a la estrategia de articulación hegemónica hasta el mismo día de la toma del poder en octubre de 1917. Empero fue Trotsky quién, en nuestra opinión, sin pertenecer a ninguna de las dos fracciones del POSDR, argumentó con más coherencia el juego estratégico de alianzas a través de su teoría de la revolución permanente y del desarrollo desigual y combinado que le daba fundamento (Molina, 2009). Tras la Revolución de Octubre el término hegemonía dejaría de tener actualidad internamente para empezar a utilizarse en los documentos externos de la Tercera Internacional. En ellos se decía que el deber del proletariado era el de ejercer la hegemonía sobre los otros grupos oprimidos en la lucha contra el capitalismo y ya no solo contra el absolutismo. En el IV Congreso, en 1922, la noción se extiende por primera vez a la función de dominación que ejercería la burguesía sobre el proletariado si lograra mantener a este dentro de los límites del corporativismo sindical (Anderson, 1981). Gramsci, que formó parte del IV Congreso, tomará el concepto de estos documentos de la Comintern.

\subsection{Las fuentes de Gramsci}

[...] Hay dos modos de defenderse: el uno con las leyes y el otro con la fuerza: el primero es propio y peculiar de los hombres, y el segundo común con las bestias. Cuando las leyes no alcanzan, es indispensable recurrir a la fuerza; y así un príncipe ha de saber emplear estas dos especies de armas [...]

(Maquiavelo, 2012)

Existen dos elementos que condujeron a la idea de hegemonía en Gramsci. El primero como se acaba de ver provino de los debates de la Tercera Internacional y el segundo de los escritos de Maquiavelo. En lo que respecta al primer elemento la originalidad de Gramsci fue trasladar el concepto desde la perspectiva del proletariado respecto de las otras clases oprimidas a la forma con la que la burguesía ejercía su poder en la sociedad occidental. En lo concerniente al segundo, Gramsci (1981) tomó de Maquiavelo (2012) la imagen del poder como centauro, medio hombre y medio bestia. Es decir, una combinación entre consentimiento y fuerza represiva. En la medida en que el elemento consensuado de poder está al frente, la hegemonía prevalece, reservando la fuerza para ser aplicada en casos excepcionales a diferencia del propio Maquiavelo que, en función de su realidad, priorizó la fuerza en detrimento del consenso (Anderson, 1981). A partir de aquí el término se convertirá en sinónimo de consentimiento frente al de dominación.

\subsection{La evolución del término}

Un grupo social es dominante sobre los grupos enemigos a los que tiende a liquidar o a someter mediante la fuerza armada y es dirigente respecto a los grupos afines $o$ aliados. Un grupo social puede, y de hecho debe, ser dirigente antes de conquistar el poder gubernamental.

(Gramsci en Anderson, 1981)

\subsubsection{El bloque histórico}

El punto de partida de Gramsci fue estrictamente leninista. En Notas sobre la cuestión meridional de 1926 afirmaba que "El proletariado puede llegar a ser la clase dirigente y dominante en la medida en que 
logre crear un sistema de alianzas que le permita movilizar a la mayoría de la población trabajadora contra el capitalismo [...]" (Gramsci en Laclau y Mouffe, 1987: 115). Al igual que en Lenin el liderazgo es aún meramente político y no intelectual ni moral. Esta transición desde el plano político al intelectual y moral será uno de los aportes que complejizarán la noción de hegemonía. Para ello Gramsci (1981) creará el concepto de bloque histórico como categoría totalizante y superadora de la antigua distinción entre base y superestructura y o sociedad civil y Estado. Un bloque histórico es un espacio de poder cementado por la ideología del actor predominante en la sociedad. Ideología no como conjunto de ideas ni como falsa consciencia sino como principios articulatorios que a través de aparatos e instituciones le dan consistencia y estabilidad a dicha totalidad (Laclau y Mouffe, 1987).

\subsubsection{Guerra de posición y contrahe- gemonía}

Para ilustrar las diferencias de circunstancias entre Rusia y Europa Occidental, Gramsci (1981) recurrió a la analogía militar. En Rusia el aparato burocrático y represor era robusto mientras que la sociedad civil no estaba bien desarrollada. Este hecho hacía posible una guerra de movimiento, insurreccional, dirigida por el partido de vanguardia de la clase obrera una vez había sido articulada la hegemonía con los otros grupos explotados. En Europa, la sociedad civil bajo la hegemonía burguesa estaba bien consolidada por lo que una guerra de movimiento insurreccional estaría condenada al fracaso a medio plazo. El estado en occidente, en sentido limitado del término, estaría bordeado y protegido por todo un sistema de fortalezas y excavaciones. La estrategia alternativa consistiría en una guerra de posición que lentamente reforzara las bases sociales de un nuevo bloque histórico liderado por la clase obrera que disputase la hegemonía a la burguesía. Para ello hacía falta crear instituciones y recursos intelectuales paralelos dentro de la sociedad existente. Significaba construir contrahegemonía dentro de la hegemonía vigente como estrategia de largo alcance (Cox, 1983). Unos años antes, Kautsky, en una famosa polémica con Rosa Luxemburg, había propuesto una fórmula de lucha para la clase obrera alemana muy parecida en su significado al de guerra de posición. Kautsky la llamó estrategia (o guerra) de desgaste frente a la estrategia de derrocamiento defendida por Luxemburg (Anderson, 1981). La diferencia entre Kautsky y Gramsci, a decir de Laclau y Mouffe (1987) era que mientras el primero abogaba por una espera a que las míticas leyes del desarrollo capitalista simplificaran los antagonismos sociales y crearan las condiciones para la desaparición del desajuste entre masas y clases y entre dirigentes y dirigidos, la teoría gramsciana de hegemonía acepta la complejidad social como condición misma de la lucha política sentando así las bases para una práctica democrática de la política compatible con la pluralidad de sujetos ( $p: 124)$.

\subsubsection{Revolución pasiva}

Gramsci (1981) distingue dos tipos de sociedades occidentales. Las que habían realizado la revolución social burguesa y establecido nuevos modos de producción y de relaciones sociales como Inglaterra y Francia; y las que habían importado elementos de un nuevo orden creado en el 
extranjero sin haber desplazado el viejo. En estas sociedades la nueva burguesía industrial no lograba alcanzar la hegemonía y se producía un estancamiento en la lucha de clases que generaba las condiciones para una revolución pasiva. Esto significaba la introducción de cambios que no implicasen la movilización de las fuerzas populares. En este escenario era propicio que se manifestara una expresión política cesarista que se elevara aparentemente por encima de las clases para garantizar el orden social a través de políticas transformistas de colaboración de clases. Dependiendo del contenido programático de estos cesarismos podrían ser más o menos progresistas o conservadores siendo este último el más representativo de la revolución pasiva. Como señaló Cox (1983) el concepto de revolución pasiva describe la condición de las sociedades no hegemónicas y es particularmente sintomática de los países no centrales del capitalismo global.

\section{Hegemonía en la Teoría de las Relaciones Internacionales}

Thus, hegemony differs from any form of relationship that implies direct management or ownership of foreign terriories. Consequently, the concept of hegemony does not cover forms of domination such as annexing, occupation or acquisition of foreign territories or populations.

(Antoniades, 2008)

\section{I El problema conceptual}

Se tiende a considerar la hegemonía en la disciplina de Relaciones Internacionales, debido a la predominancia de la tradición positivista, como un concepto que define la relación entre potencias del planeta. Es por esta visión que se presta más atención a los aspectos cuantitativos como comparar los índices del PIB, la deuda o el déficit comercial. Según Ornelas (2010) ello resulta en visiones burdas de la disputa por la hegemonía mundial. En su contra cara marxista estructuralista el declive de EEUU como potencia hegemónica estaría actualmente en fase final a causa de la crisis de valorización productiva de su economía en favor de China (Arrighi, 1999; Wallerstein, 2005; Amin, 2016). Empero, la hegemonía es más bien multidimensional. A decir de Ceceña (2004), la hegemonía no puede ser circunscrita al poder económico o militar. Para ser eficaces, estos poderes deben convencer de su infalibilidad y estar integrados en una visión de mundo capaz de brindar una explicación coherente en todos los campos. Si se retorna a Gramsci (1981) ¿Las relaciones internacionales preceden o siguen a las relaciones sociales fundamentales? Para él no había duda, las siguen. Cualquier transformación orgánica en la estructura social de un estado-nación poderoso modifica orgánicamente también las relaciones absolutas y relativas en el terreno internacional. Para Gramsci, el estado seguía siendo la entidad básica de las relaciones internacionales y el lugar donde se dan los conflictos sociales y por tanto el espacio donde se construye la hegemonía como preámbulo de una posible internacionalización de la misma. No obstante, la visión del estado de Gramsci dista mucho de la interpretación reduccionista burocrática e incluye a la sociedad civil con sus valores culturales e ideológicos hegemónicos. Desde esta perspectiva, la hegemonía en el orden mundial se fundamenta no solo en la regulación de 
los conflictos interestatales sino que también descansa en la problemática de una sociedad civil concebida globalmente, es decir, un modelo de producción económico y cultural de extensión internacional que vincula a las clases sociales de todos los países (Cox, 1983).

\subsection{Los distintos enfoques sobre la hegemonía}

Hay que dejar claro que no se pretende explicitar todas las corrientes de pensamiento de las relaciones internacionales sino solo aquellas que han hecho del concepto de hegemonía un eje transversal en sus análisis. Así por ejemplo no se mencionará ni a la escuela constructivista ni a la feminista, ni tampoco se hará referencia a los cuatro debates históricos de las relaciones internacionales a no ser que venga a colación alguno de ellos como será el caso concreto del tercer debate entre neorrealistas y neoliberales. Dicho esto, para describir las diferentes perspectivas de la idea de hegemonía en las relaciones internacionales se analizará críticamente el texto de Andreas Antoniades From theories of hegemony to hegemony analysis in international relations. Antoniades ${ }^{5}$ (2008), divide estos enfoques en dos bloques específicos; los que están dentro de la teoría de las RRII y los que están fuera. Dentro del primer bloque incluye cuatro fundamentales:

\subsubsection{El enfoque realista o convencional:}

Es la visión pragmática de la hegemonía definida por la lógica de un estado poderoso que ejerce el dominio sobre el sistema internacional. Esta superioridad es explicada por estos autores por los índi-

5. Director del Centro de Economía Política Global de la Universidad de Sussex. ces geográficos, recursos naturales, capacidad industrial, financiera y económica, capacidad militar, la educación, la moral y la unidad de la población, la calidad de la diplomacia y el gobierno y la innovación tecnológica. Entre sus máximos exponentes están Morgenthau y Robert Gilpin. El estado nación es el centro de las relaciones internacionales con leves matizaciones entre realistas y neorrealistas.

3.2.2 El enfoque neoliberal: surgió como respuesta a la corriente neorrealista de Robert Gilpin. En concreto como crítica a la Teoría de la Estabilidad Hegemónica. Dicha teoría afirma que una economía mundial liberal y abierta necesita de un poder hegemónico para su mantenimiento y estabilidad. Este argumento fue contestado por Robert Keohane (1984) en su libro After Hegemony donde asevera que un sistema internacional podría continuar funcionando a través de sus instituciones incluso después de un hipotético colapso del hegemón. De esta manera el enfoque neoliberal modificó el centro del análisis desde el sujeto de la hegemonía (el hegemón) a las condiciones y mecanismos operativos de la misma. Otro exponente de esta corriente es Joseph Nye (1990), que no menciona Antoniades y que desarrolló los conceptos de soft power y smart power. En su libro Bound to lead: the changing nature of American power, Nye señala que si EEUU quiere seguir siendo el hegemón del sistema internacional tras el fin de la Guerra Fría tiene que combinar la acción dura basada en el control de la seguridad internacional con el poder blando consistente en construir redes institucionales que le permita gestionar la creciente interdependencia transnacional. Esta combinación entre coerción y convencimiento en favor de este último se aproximaría, en nuestra opinión, al 
concepto de hegemonía gramsciano visto desde el ángulo del poder establecido. Por tanto, el poder blando (soft power) es la capacidad de organizar la agenda política de forma que configure las preferencias de los otros, es decir, la facultad de influenciar y atraer, mientras que el poder inteligente (smart power) tiene una mayor amplitud porque significa desarrollar una estrategia basada en recursos y herramientas que permitan conseguir los objetivos mediante la combinación tanto del poder duro como del poder blando (Nye, 2003). En la actualidad el poder blando se ejecuta principalmente mediante la estrategia de la diplomacia pública a través del uso de las nuevas tecnologías de comunicación con el objetivo de ejercer la influencia por parte de una entidad sobre un público extranjero (Manfredi, 2011).

\subsubsection{El enfoque gramsciano: Antoniades} (2008) lo explica fundamentalmente basándose en Cox (1983) y en una frase de Gramsci (1981) extraída de los Cuadernos de la Cárcel, a saber: "la dominación está basada en la coerción y la hegemonía en el consentimiento". (Traducción propia) (Antoniades, 2008: 3). De esta manera, la hegemonía significaría el proceso a través del cual la clase dominante de una sociedad transforma sus propios intereses y valores en sentido común para todos los miembros de la sociedad.

\subsubsection{El enfoque radical o post estructu-} ralista: para Antoniades este encuadre estaría definido por los autores que se basan en los análisis del poder de Michael Foucault. Para ello cita a dos parejas de autores, Laclau; Mouffe y Negri; Hardt. Así Laclau entiende la hegemonía como el momento en el que una particularidad específica adquiere una significación universal. De igual manera la hegemonía sería un orden discursivo independiente a las fuerzas sociales que le dan nacimiento. Para Negri y Hardt, el imperio como sinónimo de hegemonía, es un nuevo orden internacional que convierte su función vital reproductiva, es decir, biopolítica, en un elemento que asume todo individuo como propio. Por lo tanto, el imperio sería un sistema descentrado y desterritorializado de reglas que regulan la vida social desde su interior. De esta forma no ubican el sujeto de la hegemonía en ningún estado poderoso o grupo de estados ni en factores de producción sino directamente en el individuo que ha interiorizado el biopoder (Antoniades, 2008).

Respecto a los enfoques externos a la teoría de las relaciones internacionales Antoniades menciona otros tres encuadres principales:

3.2.5 El enfoque agencial: combina el enfoque convencional con el gramsciano. La hegemonía es conceptualizada como una relación entre dos agentes, el hegemón y el resto de actores del sistema. Analiza las diferentes formas de poder de una manera comparativa para ver cómo las hegemonías son construidas y mantenidas. En este sentido, John Ikemberry y Charles Kupchan han distinguido dos formas de construcción de poder hegemónicos, las que están basadas en incentivos o castigos políticos o económicos y las que se fundamentan en la emisión-recepción de ideología que reproduce el sistema desde el hegemón a los líderes de las otras naciones a través de normas y orientaciones (Antoniades, 2008).

\subsubsection{El enfoque realista crítico o estructu-}

ral: inspirado en la ontología de la estratificación social es dividido en tres niveles: empírico, fáctico y real. El empírico hace énfasis en la variable meramente material 
como el número de soldados, bases materiales y portaviones. El fáctico es el que está más allá de la apariencia normativa como la cuestión de la desigualdad de géneros; y el real hace alusión a las estructuras subyacentes de poder que marcan las tendencias y posibilidades a las dos variables anteriores como podría ser el consumo máximo que el sistema puede permitirse, por la limitante medioambiental, sin entrar en colapso. Por lo tanto, la ontología estratificada del realismo crítico permite examinar los diferentes factores que explican los diferentes tipos de hegemonía. Jonathan Joseph es uno de los autores predilectos de esta escuela (Antoniades, 2008).

\subsubsection{El enfoque movimiento de poder:} es la perspectiva que propugna el propio Antoniades relacionando los cuatro enfoques que están dentro de la teoría de las relaciones internacionales, es decir, el convencional, el neoliberal, el gramsciano y el postestructuralista. Para ello establece cuatro categorías posibles como productos de la combinación aleatoria de los cuatro enfoques mencionados en función de la respuesta que se le dé a la pregunta cuál es la naturaleza del poder y cómo este se ejerce. Así el poder puede ser externo a los sujetos (outside) o interno (inside) y puede aspirar a cambiar el comportamiento externo (out) o tratar de afectar a su identidad interna (in). Las combinaciones posibles son:

a) Outside-out: la hegemonía es vista como un poder externo que trata de imponerse a terceros a través de la superioridad en la capacidad material. Es la visión realista y neorrealista de las RRII. Los conceptos de hegemón y hegemonía se superponen. La hegemonía es el período de dominio del hegemón y cuando este declina el período colapsa. b) Outside-in: el poder se concibe como algo externo a los sujetos pero se aspira a ejercerlo mediante estrategias de consenso y no por coerción. Sin embargo, esta no desaparece sino que se reserva para los momentos de crisis del sistema. Aquí se ubicarían tanto el enfoque gramsciano como el neoliberal desde ángulos distintos.

c) Inside-out: esta combinación, según Antoniades, comparte con el outsidein su interés por generar consentimiento a través de la extensión de los valores y las ideas pero no como una estrategia agencial sino desde dentro de la comunidad política hacia fuera. El mejor ejemplo lo constituiría la Unión Europea.

d) Inside-in: la hegemonía es entendida como un aparato de biopoder difuso y descentrado que aspira al control de la vida humana desde su interior sin que, paradójicamente, se anule la autonomía del individuo. El postestructuralismo llenaría este espacio.

Antoniades (2008) manifiesta que estos cuatro enfoques están en constante interacción y se complementan en la realidad internacional compleja. De tal manera que puede deducirse, por ejemplo, que el gobierno de EEUU pueda pasar de la estrategia del outside-out al outside-in o como propone Negri, al inside-in en función del cambio de sus políticas. En el mismo sentido, Europa podría pasar del actual inside-out al outside-out en el caso de que los populismos de derechas se impongan en los próximos años.

\section{Conclusión}

Se ha realizado un recorrido sintético de la historia de la idea de hegemonía desde 
sus orígenes en la socialdemocracia rusa hasta la actualidad desde la perspectiva de las relaciones internacionales. Para ello se ha recurrido directa o indirectamente a distintos autores de referencia en la materia sin haber pretendido completar todo el abanico existente. Nos ha interesado más construir un mini relato que otorgue cierta coherencia discursiva al paradigma epistemológico de la hegemonía tan nombrado en la disciplina. No es fácil posicionarse en un debate alto complejo. Sin duda, Antoniades ha realizado una propuesta interesante al vincular cuatro de estos enfoques a través de una articulación móvil dependiente de los vaivenes políticos. Empero, a pesar de su utilidad, la fórmula analítica de Antoniades no deja de ser algo reduccionista al dejar fuera del análisis al resto de enfoques existentes. Por lo demás, ciertas asociaciones y definiciones son cuanto menos cuestionables. Por ejemplo, no creemos que se deba reducir el enfoque neogramsciano de las RRII a un texto que escribiera Robert Cox en 1983. En dicho texto que hemos trabajado, Cox limita la noción de hegemonía prácticamente a una mera relación de consentimiento en una suerte de lectura descafeinada y reformista de Gramsci. Pensamos que, en sintonía con Perry Anderson, Gramsci (1981) a pesar de sus antinomias, nunca pretendió hacer de la hegemonía un instrumento estratégico en favor del reformismo político como base de la socialdemocracia europea. Si bien es cierto priorizó el aspecto del consentimiento frente al de coerción e insurrección de las clases oprimidas en las sociedad occidentales ello fue más por cuestiones ontológicas que ideológicas. Del mismo modo parece una ligereza asociar a Laclau y a Negri en el enfoque postestructuralista. Si Laclau (1987) ha prescindido y renunciado al concepto de clase social no ha ocurrido lo mismo con Negri. Negri (2002, 2004, 2011) no es un autor postmarxista sino un marxista heterodoxo con influencias post estructuralistas. La matización es importante por cuanto Negri no ha renunciado ni a lucha de clases ni al comunismo entendido en su sentido original, esto es, como un sistema democrático alternativo al modo de producción capitalista y a la ley del valortrabajo. Además, Antoniades (2008) asocia la idea de imperio a la de hegemonía como si fueran sinónimos y menciona que para Negri "la hegemonía no está ubicada en ningún lugar porque el poder está desterritorializado y el control se realiza mediante dispositivos que se producen en el nivel del individuo." ( $p: 4)$. En nuestra opinión Antoniades mal interpreta a Negri porque en ningún texto que hayamos estudiado Negri asocia la hegemonía en sí con la idea de imperio sino que se da dentro de él de una forma híbrida entre el monarca, es decir, EEUU como estadonación, el resto del G7, las instituciones financieras internacionales y las empresas transnacionales en una suerte de alianza ultraimperialista en sentido kautskiano ${ }^{6}$ del término. Esto quiere decir que, tras la caída de la Unión Soviética, el mercado global ha estado hegemonizado por ese híbrido institucional basado ante todo en el consenso normativo e ideológico (Molina, 2018) liderado por EEUU pero lejos del supremacismo o híper imperialismo. Por lo tanto, la influencia gramsciana en Negri podría ser incluso mayor, en términos específicos relacionados con la hegemonía, que la recibida de Foucault. En todo caso son influencias comple-

6. Para Kautsky el ultraimperialismo era una tendencia implícita del imperialismo hacia el consenso entre los grandes para repartirse la tasa de ganancia y dejar de recurrir a las guerras mundiales. 
mentarias que enriquecen un enfoque marxista heterodoxo que va mucho más allá de Foucault y que tiene como base al Marx de los Grundrisse. Más allá de Negri pensamos que el contexto actual internacional está atravesando por un momento de crisis hegemónica de la globalización liberal que se debe analizar monográficamente, en nuestra opinión, desde una perspectiva crítica de la economía política internacional como sub disciplina de las relaciones internacionales.

\section{Bibliografía}

Amin, S., "El imperialismo contemporáneo", El viejo topo, volumen 336, 2016, pp. 42-51.

Anderson, P. (1981) Las antinomias de Antonio Gramsci. Barcelona: Editorial Fontamara.

Antoniades, A., "From theories of Hegemony to Hegemony analysis in International Relations". Paper presented at: 49 ISA Annual Convention. Panel: Hegemony, Security, and Defense in IR, 2008. Available at: http://sro.sussex.ac.uk/id/eprint/2175/

(Accessed: 10 Octuber 2019)

Arrighi, G. (1999) El largo siglo XX. Madrid: Akal.

Ceceña, A., "Estrategias de construcción de una hegemonía sin límites", en: Ana Esther Ceceña, compiladora. Hegemonías y emancipaciones en el siglo XXI. Buenos Aires: CLACSO, 2004, pp. 20-32. Disponible en: http://biblioteca.clacso.edu.ar/clacso/gt/20101018122244/3cecena.pdf

(Consultado: 30 Octubre 2019)

Cox, R., "Gramsci, Hegemony and International Relations", in Essay in Method, Millennium:Journal of International Studies, volumen 12, n² 2, 1983, pp.162-175. Available at: https://doi.org/10.1177/0305
8298830120020701 (Accessed: 5 September 2019)

Gramsci, A. (1981) Los cuadernos de la cárcel. México: Ediciones Era.

Keohane, R. (1984) After Hegemony: Cooperation and Discord in the World Political Economy. Princeton: Princeton University Press.

Laclau, E. y Mouffe, C. (1987) Hegemonía y estrategia socialista. Madrid: Siglo XXI.

Manfredi, J., "Hacia una teoría comunicativa de la diplomacia pública", Comunicación y Sociedad, volumen XXIV, n²2, 2011, pp-199-225.

Disponible en: http://hdl.handle. net/10171/27282

(Consultado: 25 Septiembre 2019)

Maquiavelo, N. (2012) El prícipe. Madrid: Editorial Edaf.

Molina, E. (2009) Repensando las revoluciones clásicas. Venezuela: IMMECA.

Molina, E. (2018) La filosofía política de Toni Negri. Andalucía: Atrapasueños.

Negri, A. y Hardt, M. (2002) Imperio. Barcelona: Paidós.

Negri, A. y Hardt, M. (2004) Multitud. Barcelona: Debate.

Negri, A. y Hardt, M. (2011) Commonwealth. Madrid: Akal.

Nye, J. (1990) Bound to lead: The changing nature of American power. New York: Basic Books.

Ornelas, R., "La hegemonía mundial y su disputa", Observatorio Latinoamericano de Geopolítica, 2010. Disponible en: http:// www.geopolitica.ws/document/ornelaspdf/ (Consultado: 10 Noviembre 2019)

Tucídides. (2015) Historia de la Guerra del Peloponeso. Barcelona: Editorial Juventud.

Wallerstein, I. (2005) Análisis del sistema mundo. México: Siglo XXI. 